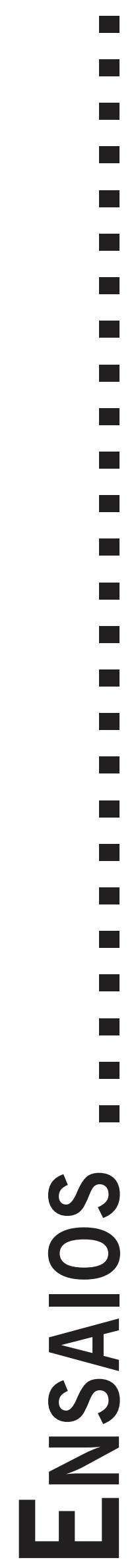




\title{
REFLEXÕES SOBRE A PRÁTICA CLÍNICA EM GESTALT-TERAPIA: POSSIBILIDADES DE ACESSO À EXPERIÊNCIA DO CLIENTE
}

\author{
Reflections about the Clinical Practice in Gestalt-Therapy: \\ Possibilities for Access to Client Experience \\ Reflexiones sobre la Práctica en Terapia Gestalt: \\ Posibilidades para el Acceso a la Experiencia del Cliente
}

Josiane Maria Tiago de Almeida

\begin{abstract}
Resumo: Este artigo pretende refletir acerca das dificuldades e caminhos possíveis para a prática clínica em Gestalt-terapia, buscando uma abordagem dialógica e fenomenológica da experiência do cliente. Considerando analogicamente a imagem de uma casa, examina a situação clínica enquanto oportunidades de acesso do psicoterapeuta ao mundo subjetivo do cliente e distingue formas de intervenção utilizando o sintoma, a experiência do cliente e suas crenças, correlacionando-as aos processos de explicação e compreensão dos significados trazidos ao processo psicoterapêutico. Finalmente, pondera sobre o papel da linguagem como fator de ressignificação das vivências e significados trabalhados no contexto da psicoterapia, ressaltando a necessidade de não perder de vista a pessoa em sua integralidade.
\end{abstract}

Palavras-chave: Gestalt-terapia; Prática Clínica; Fenomenologia; Abordagem Dialógica.

Abstract: This article intends to think about difficulties and possible ways to Gestalt Therapy’s practical clinic, searching for a phenomenological and dialogical approach to client's experience. Analogically considering the image of a house, studies the clinical situation as an opportunity for the psychotherapist to access the client's subjective world and find ways of touching the client through his symptoms, experiences and beliefs, linking all of them to a process of explanation and understanding of its meanings. Finally, wonders about language's function to reframe experiences and feelings dealt during psychotherapy, emphasizing the need of thinking on the whole person, considering his integrality.

Keywords: Gestalt-therapy; Clinical Practice; Phenomenology; Dialogical Approach.

Resumen: Este artículo reflexiona sobre las dificultades y los posibles caminos para la práctica clínica en terapia Gestalt, la búsqueda de un enfoque fenomenológico y dialógica de la experiencia del cliente. Teniendo en cuenta de manera similar a la imagen de una casa, se examina la situación clínica como oportunidades para el acceso al mundo subjetivo de la psicoterapeuta y el cliente que distingue a las formas de intervención a través del síntoma, la experiencia del cliente y las creencias, correlacionándolos con los procesos de explicación y la comprensión de significados aportado al proceso psicoterapéutico. Por último, reflexionar sobre el papel del lenguaje como un factor que la redefinición de las experiencias y los significados trabajado en el contexto de la psicoterapia, haciendo hincapié en la necesidad de no perder de vista de la persona en su totalidad.

Palabras-clave: Terapia Gestalt; La Prática Clínica; Fenomenología; Enfoque Dialógico.

A prática clínica configura-se, principalmente no inicio de nossa formação, em um campo de difícil atuação. Diferentemente de outras profissões, em que é possível uma apropriação objetiva do que é necessário fazer para que se cumpra a tarefa, a prática clínica surge diante de nós como um desafio, muitas vezes, como um mistério. Feijoo (2000, p. 15), discutindo acerca dos percalços do processo terapêutico, traça o esboço das complexidades de sua prática, afirmando que "Embora teoricamente se discuta muito, na prática, sabe-se pouco sobre o que acontece nesse processo."

Em busca de uma melhor instrumentação, recorremos às muitas especializações disponíveis no universo teórico que é a psicologia. Cada especialização, por sua vez, sintonizada com sua fundamentação, vai priorizar, no funcionamento da psique humana, determinados aspec- tos em detrimento de outros, e tal ênfase, naturalmente, orienta a metodologia empregada no consultório.

Com a Gestalt-terapia não é diferente. Abordagem psicoterapêutica fundada por Fritz e Laura Perls na década de 1940, possui uma vasta bagagem teórica fundamentada na fenomenologia, no existencialismo dialógico, no Holismo e na Teoria de Campo (Yontef, 1998) que orienta e conduz a um modo característico de atuação.

A construção de um modus operandi que seja realmente coerente com aquela bagagem é um tema recorrente nos trabalhos e discussões hoje apresentados nos congressos de Gestalt. Discute-se a necessidade da definição de termos próprios, a necessidade de uma teoria da personalidade que oriente a prática clínica, de uma teoria psicopatológica, enfim, existe uma preocupação unânime sistematizar aquela teoria para que 
se possa cada vez mais fundamentar e dar consistência à pratica.

No consultório, essa necessidade se presentifica na dúvida que em momentos assoma o psicoterapeuta a respeito do que focar, de qual intervenção empregar a serviço do cliente e em consonância com as definições que postulamos acerca do humano. O gestalt-terapeuta se depara com uma série de elementos que podem, num dado momento, ser objeto de nossa intervenção. Esses elementos pertencem a categorias diversas: coisas que o cliente nos fala, coisas que ele nos mostra em seu corpo, coisas que ele nos sinaliza por meio de sua postura, gestos, entonação. Essas “pistas” nos apontam vias possíveis para intervir em busca de uma compreensão mais acertada a respeito do funcionamento geral daquela pessoa em particular. Todavia, qual dessas pistas seguir?

Temos em nosso auxílio, dentre outras, duas ferramentas básicas que apóiam a prática clínica gestáltica e nos ajudam a elucidar essa questão: a abordagem dialógica e o método fenomenológico. A postura dialógica nos chama a atenção para a importância do vínculo estabelecido entre terapeuta e cliente. Hycner (1995) é um dos autores que tratam desse tema. Apoiado nos escritos de Hans Trüb, ele nos ensina que é o relacionamento estabelecido com o terapeuta que permite ao cliente desvelar seus conflitos, tristezas, expectativas, enfim, compartilhar seu mundo interno e restaurar as conexões que foram se perdendo ao longo da vida. Desse modo, ele valida a constatação de que "Como psicoterapeutas não podemos indicar a verdade que temos, mas somente a verdade que buscamos entre nós, entre médico e paciente." (Trub, 1952/1964, pp. 504-505, citado por Hycner, 1995, p. 71, grifos do autor).

Já o método fenomenológico nos instrumentaliza na exploração do mundo inter e intrapsíquico do cliente. Ribeiro (1994, p. 15) sintetiza dizendo que "Trabalhar fenomenologicamente é tentar ficar com a realidade como é em si, é trabalhar a partir dela. É ver o fenômeno como a realidade primeira e a partir dele e só dele caminhar para a compreensão do que significa ir além do fenômeno."

O conceito de fenômeno, enquanto aquilo que se mostra e enquanto ponto de partida para o trabalho terapêutico, resume a idéia de que é preciso ter um foco, algo que se constitua como figura e que nos permita caminhar em direção à totalidade.

O cliente nos oferta sintomas, emoções, vivências, crenças. Como tais dimensões da existência podem ser delineadas e manejadas pelo psicoterapeuta da abordagem gestáltica, mantendo a pureza do que nos é trazido, conservando o fenômeno "tal e qual se mostra" e oferecendo ao cliente a possibilidade de uma releitura de sua própria experiência? Essa é a questão que norteia nossa reflexão a respeito da prática clínica em Gestalt-terapia. Nosso objetivo aqui é olhar cada uma dessas dimensões, considerando em que medida elas nos proporcionam a oportunidade de cumprir com presteza esse mister.

\section{Diversas Portas, Muitos Caminhos...}

A prática clínica se defronta com aspectos múltiplos da natureza humana manifestos sob diversas formas. Isso pode ser ilustrado utilizando, como analogia, a imagem de uma casa. Estamos diante de uma casa: nosso cliente. Reflitamos.

O conceito casa, em si mesmo, possui uma permanência em qualquer tempo e lugar que o define em sua essência, a despeito da singularidade de cada casa específica. Todavia, nem a essência, nem a singularidade, isoladamente, definem o ser único daquela casa. Da mesma forma, tal identidade seria impensável se somente considerássemos janelas, portas, telhado, pois precisamos ter a idéia de casa como um todo antes de considerarmos suas partes. Se meu desejo é conhecer esta casa, em particular, eu preciso entrar em contato com ela: escolher uma via de acesso ou uma forma de abordagem dentre as diversas possíveis. Nenhuma via de acesso é em sua natureza melhor que outra. Seja como for, ao estabelecermos nosso contato com a casa, uma intervenção já está sendo feita e cada lugar desses por onde formos entrando vai nos fornecer uma perspectiva válida da singularidade e da comunalidade que, juntas, constituem esta casa em especial em contato conosco.

O cliente pode ser comparado a essa casa. Considerado em suas múltiplas manifestações, ele acena com diversas portas, janelas, vias de acesso. A tarefa do psicoterapeuta gestáltico é dar um acolhimento dialógico e fenomenológico a essas manifestações do cliente, sem permitir que seus próprios vieses interfiram negativamente no processo sem, contudo, esquecer que é um participante ativo na constituição dessa relação.

Vamos examinar mais de perto estas portas de entrada ao mundo do cliente, tentando examinar o que cada uma pode nos oferecer.

\section{Porta $n^{\circ}$ 1: 0 Sintoma - 0 Caminho da Explicação}

Na grande parte das vezes, o cliente ao buscar a psicoterapia tem uma demanda: uma queixa somática, uma dificuldade relacional com alguém com quem ele precisa conviver, uma perda não superada, entre outras. Esse desconforto é, talvez, a primeira oportunidade para que o psicoterapeuta participe da dinâmica existencial do cliente e possa começar a construir um vínculo de confiança.

Ginger e Ginger (1995, p. 161) afirmam que "Em Gestalt, o sintoma corporal é deliberadamente utilizado como 'porta de entrada' que permite um contato direto com o cliente, respeitando a via que ele mesmo 'escolheu', embora, com freqüência, involuntariamente."

Esse sintoma, essa demanda ou queixa representa, geralmente, uma falência nas possibilidades de a pessoa lidar com suas dificuldades e ela tem necessidade de en- 
tender o porquê do seu sofrimento; busca as causas perguntando-se: “Quem começou a discussão?” "Por que eu disse aquilo?" "Por que tudo deu errado?". "Por que eu não dou conta?" Por quê?

A legitimidade de seu questionamento encontra suporte na necessidade humana de dar um sentido à vida. Procuramos a todo o momento captar a linearidade dos acontecimentos a nossa volta, resgatando a historicidade daquilo que estamos vivendo. O sentido que tanto almejamos quase sempre é buscado nessa perspectiva histórica da existência, num exercício de explicar a realidade segundo essa lógica.

A psicoterapia deve, sem prejuízo de outras funções, auxiliar a pessoa a reencontrar seu próprio sentido. Muitas vezes, é preciso mesmo que o cliente nos conte de sua vida, de seu contexto; como se sua fala nos inserisse num cenário: o cenário de sua vida. Concorde com essa postura, Ribeiro (1999) nos ensina que "Para entender um sintoma temos que entender a vida, a existência de quem as vive, porque somente a vida contém a essência do sentimento existencial de cada um.” (Ribeiro, 1999, p. 104).

Porém, esse é um momento delicado do processo psicoterapêutico. A busca pelas causas de suas ações pode se tornar extremamente sedutora para o cliente, utilizandoas como justificativas de suas ações. Contudo, encontrálas quase nunca traz alívio.

A Gestalt-terapia postula, amparada na Teoria de Campo, que o psiquismo não se organiza exclusivamente por meio de uma sucessão linear de causa e efeito, mas sim envolto numa multiplicidade de eventos que se organizam de formas sistêmicas, formando teias de relações que não se determinam, mas que, de outra forma, se interpenetram. O conceito de campo referido por Gary Yontef (1998) ilustra tal proposição quando afirma que o campo é "Uma totalidade de forças mutuamente influenciáveis que, em conjunto, formam uma fatalidade interativa unificada.” (pág.185). Estamos, a todo instante, imersos em uma complexidade infindável de estímulos, vivências, experiências que não podem ser restritas a uma linha do tempo.

Assim, a tarefa do Gestalt-terapeuta demanda propiciar ao cliente a compreensão da totalidade das circunstâncias em que está inserido, muito mais do que apenas perseguir seus “porquês”. Em que pese a importância de nos explicarmos enquanto seres históricos, a busca de um sentido somente se justifica sem prescindirmos das vivências em si mesmas, denominadas experiências.

\section{Porta n 2 - A Experiência - 0 caminho da Compre- ensão}

Na psicoterapia de abordagem gestáltica, a experiência do cliente é sagrada. Respeitá-la, acolhê-la, deter-se na sua contemplação é, ao mesmo tempo, dever, compromisso e desafio. De consequência, formular uma conceituação de experiência nos parece importante.

Intuitivamente, sabemos que a experiência relacionase àquilo que sentimos, àquilo que vivemos "na pele". Considerando a semântica da palavra experiência, encontraremos diversas acepções tais como: ensaiar, avaliar, executar, tentar, sentir (Houaiss \& Villar, 2001). Curiosamente, o verbo experimentar, que é sinônimo de experienciar, classificado gramaticalmente como um verbo transitivo direto. Assim sendo, tais verbos exigem um complemento, eles não têm razão de ser sem algo que lhes complemente o sentido. Ademais, é um verbo transitivo que necessita de um objeto direto, logo, para que seu sentido se integralize, esse complemento tem que ser capaz de entrar em relação direta com o verbo ao qual se refere, sem a intermediação de uma preposição. Dessa forma, ao menos primariamente, a ação de experimentar diz respeito a algo que esteja presente no tempo (objetivo ou subjetivo) e no espaço (externo ou interno), em contato direto conosco. Polster e Polster assinalam esse caráter imediato da experiência quando afirmam que "A primazia da experiência está ligada de forma inextrincável à primazia do presente" (Polster \& Polster, 2001, p. 30).

Podemos dizer, então, que a experiência é uma ação aqui-e-agora, dotada de imediatez e concretude. O veículo da sua vivência é o corpo. Por meio dele, o mundo entra em nós e nós participamos do mundo, alterando-o e sendo alterados por ele. O produto primário dessa interação é essa experiência cotidiana, produtora de conhecimento vivencial, intelectual, emocional e relacional. Portanto, a experiência está na base de todo aprendizado humano. Sua relevância é tal que Perls, Hefferline e Goodman (1997) postulam que a tarefa da terapia seria

(...) analisar a estrutura interna da experiência concreta, qualquer que seja o grau de contato desta; não tanto o que está sendo experienciado, relembrado, feito, dito, etc., mas como o que está sendo relembrado é relembrado, ou como o que é dito é dito, com que expressão facial, tom de voz, sintaxe, postura, afeto, omissão, consideração ou falta de consideração para com a outra pessoa etc. (Perls et al., 1997, p. 46).

Enquanto psicoterapeutas, devemos ter, segundo esses autores, um olhar atentivo para o modo como recebemos os fatos diários em nosso corpo, revelando nossa vivência dos fatos em lugar dos fatos propriamente ditos. Fenomenologicamente, o "como" nos conduz invariavelmente "ao modo que”, à descrição do real em nós, fazendo nos mergulhar nessa organicidade tão presente e, ao mesmo tempo, tão despercebida. A fenomenologia, conforme dito anteriormente, nos instrumentaliza na exploração desse mundo inter e intrapsíquico do cliente pretendendo compreendê-lo muito mais do que explicálo. Feijoo (2000) conceitua primorosamente aquilo que 
considera o objetivo da psicologia fenomenológica, discorrendo que ela

(...) visa descrever com rigor, e não deduzir ou induzir; mostrar e não demonstrar, explicitar as estruturas em que a experiência se verifica e não expor a lógica da estrutura; por fim, deixar transparecer na descrição da experiência suas estruturas e não deduzir o aparente por aquilo que não se mostra. (Feijoo, 2000, p. 33)

Descrever implica acessar a dimensão emocional do homem que é também sua dimensão energética, visto que as emoções são responsáveis pelo colorido, pelo tom e pela modulação daquilo que é vivido, gerando interesse e excitação e imprimindo em nós a marca da realidade. Elas estão fora do domínio reflexivo da mente, obedecendo apenas ao fluir da vida. Encontram-se, portanto, relacionadas aos aspectos mais arcaicos de nosso desenvolvimento, condensando vivências e traduzindo nossa história emocional.

Ginger e Ginger postulam que o Gestalt-terapeuta deve ser como o "(...) encanador, que vela para assegurar uma circulação fluida (das emoções), para desobstruir canais, para evitar tanto a seca quanto a inundação." (1995, p. 164) possibilitando ao cliente apropriar-se de seus próprios sentimentos e emoções.

É essa postura metodológica compreensiva do Gestaltterapeuta que o possibilita entrar nesse território emocional de forma respeitosa e acolhedora. De que outra forma poderíamos ter a ousadia de abrigar o sofrimento humano, muitas vezes sem palavras, senão compreendendo-o em sua acepção mais própria de conter em si (Houaiss \& Villar, 2001), de permitir incluir-se na vivência dessa outra pessoa que o procura usando de sua própria experiência de ser humano, de sua própria vivência!

Zinker (2007) assim se manifesta acerca desse vínculo de natureza tão peculiar que se estabelece entre terapeuta e cliente, ressaltando que a humanidade do primeiro, em forma de afeto, provê a confiança recíproca, sustentáculo de todo processo psicoterapêutico:

O amor altruísta do terapeuta promove a confiança. Como o processo da terapia lida frequentemente com as partes mais vulneráveis da pessoa, a confiança deve estar sempre presente para que as duas partes se permitam revelar seus sentimentos. É esse “amor", em todas as suas formas, que alimenta o processo criativo entre o cliente e o terapeuta. (Zinker, 2007, p. 19)

É esse “amor" dito por Zinker (2007) que tem o condão de favorecer ao cliente sentir-se compreendido por outro ser humano em sua própria experiência de acolhimento e aceitação e, talvez, ele mesmo possa, num movimento paradoxal, voltar a si mesmo amorosamente, compreendendo-se, acolhendo-se e aceitando-se.

\section{Porta n 3: Crenças - 0 Caminho do Significado}

O ser humano se expressa majoritariamente por meio da linguagem. É por meio da fala que ele é capaz de acumular e transmitir sua cultura, sua longa jornada de desenvolvimento.

A linguagem é a expressão máxima da capacidade humana de simbolização da experiência. Ao utilizarmos um símbolo lingüístico para representar um objeto concreto construímos uma ponte entre o mundo real e o mundo simbólico que constitui a subjetividade (Coll, Palacios \& Marchesi, 1995). Quando uma experiência é simbolizada, ela ganha significado e, apropriada pelo sujeito, encaixa-se em sua vida, ganhando um lugar que é a síntese integradora daquilo que já passou, daquilo que é e do que pode vir a ser.

Essa capacidade de representar o mundo é base de toda a nossa vida intelectiva. Os pensamentos são a fala interiorizada; possibilitam-nos a formação de conceitos, crenças e significados, nos distanciando da experiência concreta e nos oferecendo a condição de refletir acerca do vivido (Coll et al., 1995).

A maior parte dos sistemas psicoterápicos tem na fala seu carro-chefe. Assim, a escuta e a fala constituem-se nos instrumentos essenciais de comunicação terapêutica e, justamente em decorrência disso, devemos observar cuidadosamente o modo como as palavras são proferidas: com que intenção, com que entonação, em que momento. Seu grande benefício pode perigosamente transmutar-se em grande ameaça: o afastamento do real. À medida que trabalhamos verbalmente devemos nos ancorar no vivido, na experiência, fugindo ao perigo das palavras vazias de sentido e resgatando, para tanto, o linguagem paraverbal que acompanha as palavras. É a experiência que as preenche de significado, originando crenças e norteando comportamentos.

Significar é criar forma, resgatar o que se aloja nas ínfimas partículas de nosso corpo e de nossa alma e traduzir tudo isso num conceito que faça sentido e que seja leal à experiência. Construímos assim o significado de nossa vida, que precisa ser habitualmente reconectado à experiência, deixando a dimensão puramente mental e reintegrando-se as nossas vivências. A busca do significado, com efeito, pode nos distanciar da experiência, mas encontrá-lo, então, nos reaproxima dela. Desse modo, quando um pensamento ou crença está ancorado na experiência, ele a revivifica, dando-lhe efetividade, como sustenta Yontef: "A Gestalt-terapia não enfatiza o pensamento que inibe a experiência (conduta obsessiva) e encoraja o pensamento que dá suporte à experiência." (1998, p. 23) 


\section{A Casa: A Integração}

Finalmente, é a pessoa que nos interessa, em sua absoluta integridade. Por compromisso de coerência, não podemos pensar em meia-casa, em meia-pessoa, em meiavivência. Não perdemos de vista o perfil da casa, seu pédireito, sua conformação clássica ou modernista. Jamais. A opção de uma porta ou outra não nos distrai de nossa real e infinita busca pela compreensão e apreensão da pessoa como um todo, e é justamente esse objetivo que dá sentido ao nosso caminhar pelas diversas expressões do humano em nosso cliente.

A palavra 'integrar' resume bem nosso percurso reflexivo e, felizmente, o processo terapêutico. Integrar é tornar inteiro, completar, reunir (Holanda, 2009). As vias de acesso, como proposto nessa reflexão, devem ser tomadas não como recurso de análise: fragmentando, dividindo, mas antes, como um recurso de integração, permitindo ao Gestalt-terapeuta estar com seu cliente sem tentar decompô-lo em pedaços, mas respeitando a unidade essencial que o define.

\section{Referências}

Coll, C., Palacios, J., \& Marchesi, A (1995). Desenvolvimento Psicológico e Educação: Psicologia Evolutiva. Porto Alegre: Artes Médicas.

Feijoo, Ana Maria L. C. (2000). A escuta e a fala em psicoterapia. São Paulo: Vetor.

Ginger, S., \& Ginger, A. (1995). Gestalt: Uma Terapia do Contato. São Paulo: Summus.

Holanda, A. B. (2009). Minidicionário Aurélio da Língua Portuguesa $\left(7^{\mathrm{a}}\right.$. ed. revista e atualizada). Curitiba: Editora Positivo.

Houaiss, A., \& Villar, M. de S. (2001). Dicionário Houaiss da Língua Portuguesa. Rio de Janeiro: Objetiva.

Hycner, R (1995). De Pessoa a Pessoa: psicoterapia dialógica. São Paulo: Summus.

Perls, F., Hefferline, R., \& Goodman, P. (1997). Gestalt-terapia (2a .ed.). São Paulo: Summus.

Polster, E., \& Polster, M. (2001). Gestalt-terapia Integrada. São Paulo: Summus.

Ribeiro, J. P. (1994). Gestalt-terapia: O Processo Grupal: uma abordagem fenomenológica da teoria do campo e holística. São Paulo: Summus.

Ribeiro, J. P. (1999). Gestalt-terapia de Curta Duração. São Paulo: Summus.

Yontef, G. M. (1998). Processo, Diálogo e Awareness: ensaios em Gestalt-terapia. São Paulo: Summus.

Zinker, J. (2007). Processo Criativo em Gestalt-terapia (M. S. M. Netto, Trad.). São Paulo: Summus.
Josiane Maria Tiago de Almeida - Psicóloga Clínica, graduada pela Pontifícia Universidade Católica de Goiás, especialista em Gestaltterapia pelo Instituto de Treinamento e Pesquisa em Gestalt-terapia de Goiânia (ITGT/PUC-GO). Email: jmtal@hotmail.com

Recebido em 13.04.10 Aceito em 18.08.10 